\title{
Operation Rule of Steam Ejector and Influence Analysis of Ejection Position
}

\author{
Zhao Jinhui ${ }^{1}$, Xia Yongbo ${ }^{1}$, Wang Yufeng ${ }^{1}$, Liu Tao ${ }^{1}$, Zhang Lijun $^{1}$, \\ ${ }^{1}$ (School of Mechanical and Power Engineering, Zhengzhou University, Zhengzhou, Henan, 450000, China)
}

\begin{abstract}
In order to analyze the operation rule of steam ejector used in sewage treatment field, this paper established the mathematical model of steam ejector, simulated the internal flow state, analyzed the influence rule of external parameters on the performance of steam ejector, and analyzed the influence rule of ejector position on the water production ratio of steam ejector multi-effect evaporation desalination system. The research results show that under the same steam ejector structure, as the pressure of the working steam increases, the mixing and disturbance of the working steam and the ejected steam become more intense, and the diamond shock wave structure increases. As the pressure of the ejected steam increases, the momentum exchange effect of the shear blending of working steam and ejected steam is accelerated, and the speed increase rate becomes larger, and the diamond shock wave structure gradually gathers toward the nozzle. As the pressure rise of the ejected steam inlet and outlet increases, the backflow phenomenon near the wall in the mixing chamber becomes more serious, and the diamond shock wave structure is reduced. With the forward movement of the ejector position of the thermal steam compressor, the pressure of the ejected steam increases, and the water production ratio of the steam ejector multi-effect evaporation seawater desalination system shows a downward trend. Therefore, choosing appropriate working condition parameters can effectively improve the working performance of steam ejector and improve its operating efficiency in the field of sewage treatment.
\end{abstract}

\section{Introduction}

In industrial production, a large amount of untreated sewage is discharged directly, causing serious water pollution. ${ }^{1}$ Conventional sewage treatment methods, such as membrane method, physical-chemical method and activated sludge method, have high cost and complex process, which restrict the advanced treatment of sewage. The coupling system of steam ejector (TVC) and multieffect evaporator (MED), as a low-cost and highefficiency sewage treatment method, has become one of the research hotspots of industrial sewage treatment technology.

At present, the research on steam ejector mainly focuses on the design optimization of structure and parameters of steam ejector, the improvement of ejector performance and the reduction of energy consumption of coupling system. Shuai $\mathrm{Lu}$ et al. ${ }^{[2]}$ established the optimization model of concurrent MED-TVC coupling system, and optimized the MED-TVC coupling system by using the optimization solver Lin90 with the water production ratio as the objective function. Cai Haitao et al. ${ }^{[3]}$ discussed the parameter design of steam ejector by taking the domestic large-scale low-temperature multieffect seawater desalination project as an example.

The analysis of the present situation shows that there are few studies on the influence of operating parameters on the steam flow state in the steam ejector and the influence of determining the injection position on the steam ejector, which greatly affects the research and optimization of the performance of the coupling system between the steam ejector and the multi-effect evaporator. Therefore, in this paper, the internal flow state of steam ejector is numerically simulated, and the influence of operating parameters on the flow of steam ejector is analyzed, and the influence of ejector position on the water production ratio of steam ejector multi-effect evaporation desalination system is determined.

\section{Working mechanism of steam ejector}

Steam ejector (Fig.1) is the key equipment used in the coupling system of steam ejector and multi-effect evaporator. High-pressure working steam is accelerated and depressurized through the nozzle, and the pressure at the outlet of the nozzle is lower than that of the ejected steam. The steam ejector uses the pressure difference to inject the low-pressure steam generated by the multi-effect evaporator, which is mixed through the nozzle to generate the required steam. The steam pressure and Mach number change with the internal position of the steam ejector (Fig.2). The steam ejector is coupled with the multi-effect evaporator, which can greatly improve the water-making economy of the multi-effect evaporator device, recover industrial low-quality steam, and realize the integration of energy saving and emission reduction.

*Corresponding author: zhanglijun@zzu.edu.cn 


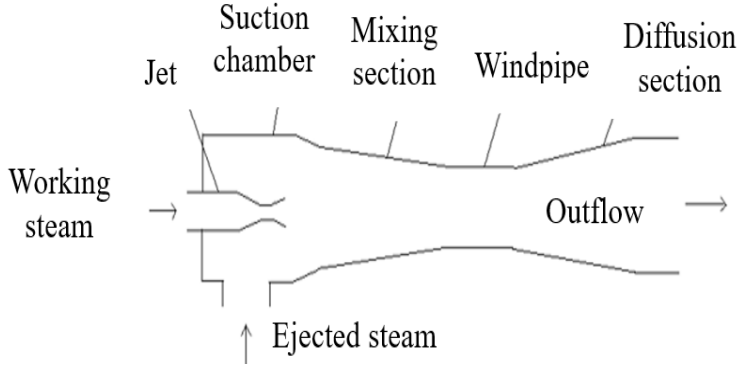

Fig. 1. Schematic diagram of steam ejector

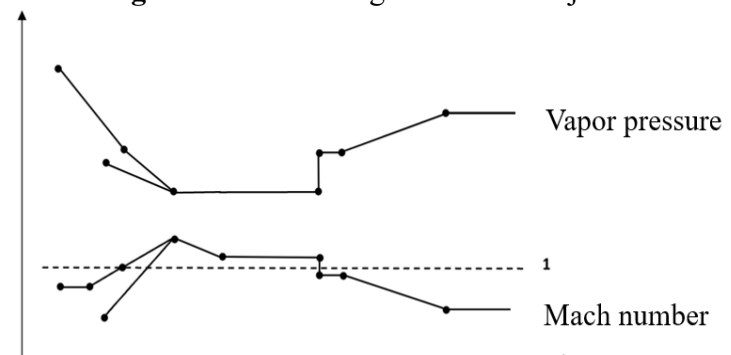

Fig. 2. Variation of steam pressure and Mach number with steam ejector position

\section{of steam ejector}

\subsection{Size selection of steam ejector}

Based on SH/T 3118-2000 Petrochemical Steam Ejector Technical Specification ${ }^{4}$, the thermodynamic calculation of thermal steam compressor is carried out, and its working nozzle, ejector chamber, mixing chamber and diffuser chamber are designed. The main dimensions are designed and calculated as follows:

The structural dimensions shown in Tab. 1 are designed as the main structure of the steam ejector model.

\section{Establishment of mathematical model}

Table 1. Steam ejector model size

\begin{tabular}{|c|c|c|c|c|c|}
\hline Project name & $\begin{array}{c}\text { Inlet diameter of } \\
\text { working steam D1 }\end{array}$ & $\begin{array}{c}\text { Inlet diameter of } \\
\text { ejected steam D2 }\end{array}$ & $\begin{array}{c}\text { Outlet diameter } \\
\text { of reducer D3 }\end{array}$ & $\begin{array}{c}\text { Outlet diameter } \\
\text { of shrink tube D4 }\end{array}$ & $\begin{array}{c}\text { Outlet diameter of } \\
\text { diffuser pipe D5 }\end{array}$ \\
\hline Numerical value & $22 \mathrm{~mm}$ & $29 \mathrm{~mm}$ & $35 \mathrm{~mm}$ & $18 \mathrm{~mm}$ & $50 \mathrm{~mm}$ \\
\hline Project name & Tee length L1 & $\begin{array}{c}\text { Length of reducer } \\
\text { L2 }\end{array}$ & $\begin{array}{c}\text { Shrinkage tube } \\
\text { length L3 }\end{array}$ & $\begin{array}{c}\text { Mixing tube } \\
\text { length L4 }\end{array}$ & $\begin{array}{c}\text { Diffuser pipe } \\
\text { length L5 }\end{array}$ \\
\hline Numerical value & $128 \mathrm{~mm}$ & $35 \mathrm{~mm}$ & $58 \mathrm{~mm}$ & $18 \mathrm{~mm}$ & $60 \mathrm{~mm}$ \\
\hline
\end{tabular}

\subsection{Establishment of the governing equation}

The steam ejector meets continuity equation, energy conservation equation and momentum conservation equation in operation, and the mathematical model is as follows:

Continuity equation: $\frac{\partial}{\partial x_{i}}\left(\rho u_{i}\right)=0$

Energy conservation equation: $\rho u_{i} \frac{\partial e}{\partial x_{i}}=-p \frac{\partial u_{i}}{x_{i}}+$ $\frac{\partial}{\partial x_{i}}\left(\lambda \frac{\partial T}{\partial x_{i}}\right)+\frac{\partial u_{i}}{\partial x_{j}} \mu\left(\frac{\partial u_{i}}{\partial x_{j}}+\frac{\partial u_{i}}{\partial x_{i}}\right)$

Momentum conservation equation: $\rho u_{i} \frac{\partial u_{i}}{\partial x_{i}}=$ $-\frac{\partial p}{\partial x_{i}}+\frac{\partial}{\partial x_{i}}\left(\lambda \frac{\partial u_{i}}{\partial x_{i}}\right)+\frac{\partial}{\partial x_{j}}\left[\mu\left(\frac{\partial u_{i}}{\partial x_{j}}+\frac{\partial u_{i}}{\partial x_{i}}\right)\right]$

$\rho$ is the density of the fluid, $\mathrm{kg} / \mathrm{m}^{3} ; \quad e$ is the unit potential energy of the fluid, $\mathrm{J} / \mathrm{kg} ; \lambda$ is the heat transfer coefficient of the fluid, $\mathrm{W} /\left(\mathrm{m}^{2} \cdot \mathrm{K}\right) ; \mu$ is the dynamic viscosity of the fluid, $\mathrm{Pa} \cdot s$.

\subsection{Calculation model and grid division}

A three-dimensional model of the steam ejector (Fig.3) is established, ignoring the influence of the cylindrical section of the ejector inlet of the steam ejector, thus simplifying the vertical inflow into the ejector inlet into axial inflow. The difference between the calculation results of this simplified model and the calculation results of the complete three-dimensional model is very small and can be ignored ${ }^{[5]}$. The half two-dimensional axisymmetric steam ejector model is divided into grids, and the wall area is encrypted (Fig.4).

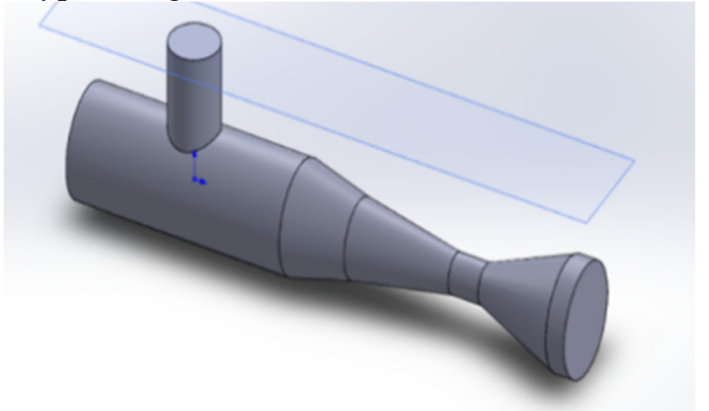

Fig. 3. 3D model of steam ejector

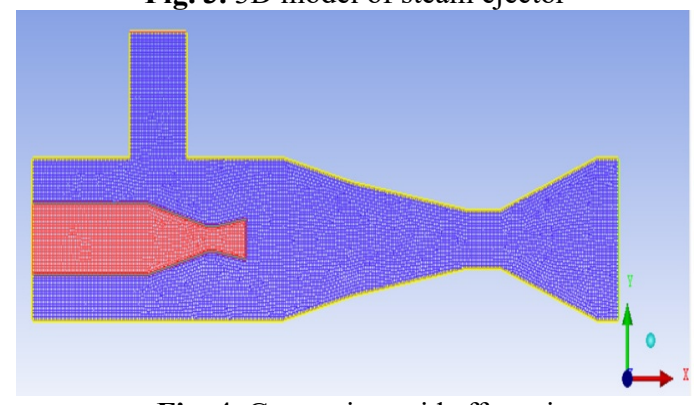

Fig. 4. Generating grid effect picture

The model adopts implicit solution based on pressure, setting the fluid domain as water-steam mixture. The pressure and velocity fields are Coupled by the coupled 
scheme, and the second-order upwind scheme. The convergence accuracy of residual error is set to $10^{-5}$, and the calculation steps are 10,000 steps. The boundary conditions are set as follows: The boundary conditions of pressure inlet are adopted, the steam are fed by independently. Outlet steam is set as the boundary condition of superheated steam static pressure outlet. The conditions of no slip and no infiltration are adopted for the wall surface.

\section{Steam ejector performance optimization analysis}

\subsection{Influence analysis of working steam pressure}

With the ejected steam pressure at $0.1 \mathrm{MPa}$ and the pressure rise at the inlet and outlet of the ejected steam constant at $10 \mathrm{kPa}$, simulation studies were carried out on the working steam with pressures of $0.32 \mathrm{MPa}, 0.34 \mathrm{MPa}$ and $0.36 \mathrm{MPa}$, respectively, and the results are shown in Figure 6 . With the increase of working steam pressure, the mixing and disturbance of working steam and ejected steam become more severe, and the DIA shock wave structure increases, gradually extending to the outlet of the mixing section, and choking occurs in the mixing section, causing partial backflow of fluid.
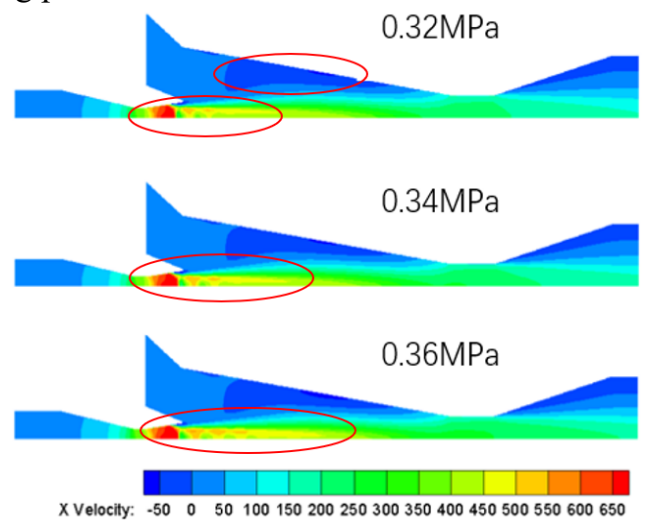

Fig. 5. Velocity nephogram of working steam under different pressures

\subsection{Influence analysis of ejected steam pressure}

With the working steam pressure at $0.34 \mathrm{MPa}$ and the pressure rise at the inlet and outlet of the ejected steam constant at $10 \mathrm{kPa}$, the ejected steam with pressures of $0.10 \mathrm{MPa}, 0.11 \mathrm{MPa}$ and $0.12 \mathrm{MPa}$ were simulated, and the velocity nephogram is shown in Figure 7. Under the same steam ejector structure, with the increase of the ejected steam pressure, the working steam and the ejected steam are mixed at the nozzle outlet, the momentum exchange effect of shear mixing is accelerated, the speed increase is increased, and the DIA shock wave structure gradually gathers to the nozzle.
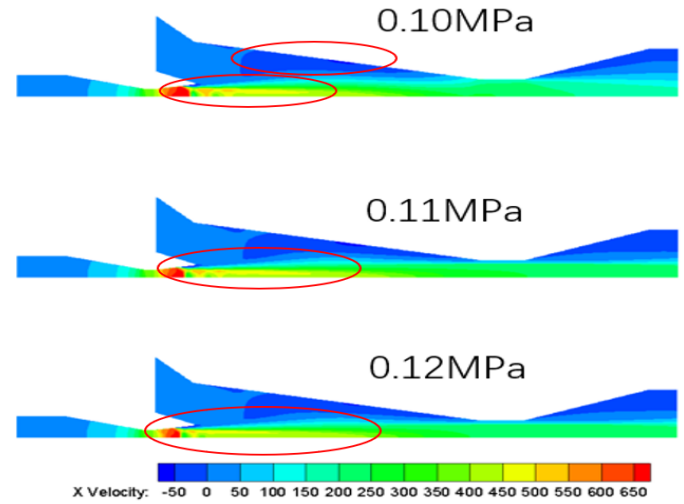

Fig. 6. Velocity nephogram of ejected steam at different pressures

\subsection{Analysis of the influence of pressure rise}

The working steam pressure is kept at $0.34 \mathrm{MPa}$, and the ejected steam pressure is kept at $0.11 \mathrm{MPa}$, and the simulation research is carried out under the pressure rise of $10 \mathrm{kPa}, 15 \mathrm{kPa}$ and $20 \mathrm{kPa}$ respectively, and the velocity nephogram is shown in fig. 8. With the increase of the pressure rise at the inlet and outlet of the ejected steam, the backflow phenomenon near the wall in the mixing chamber becomes more and more serious, and the DIA shock wave structure decreases.
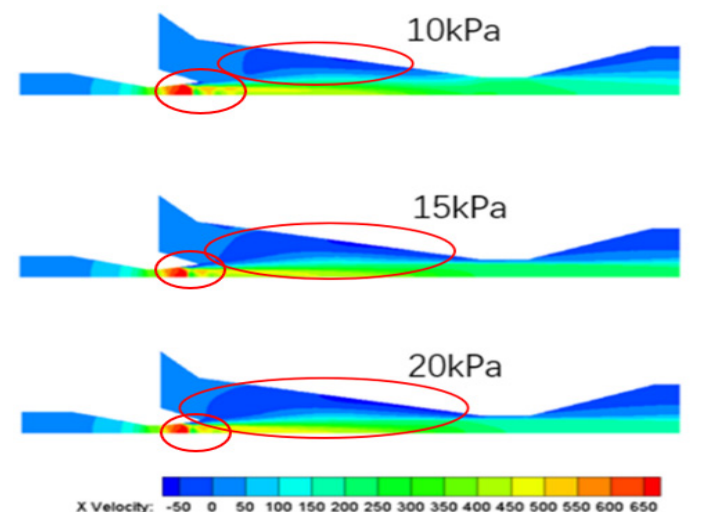

Fig. 7. Velocity nephogram of mixed steam under different pressure rise

\section{Influence rule of ejector position of steam ejector}

\subsection{Effect of evaporator efficiency on water production ratio}

The water production ratio is an important index reflecting the performance of seawater desalination system. The higher the GOR, the higher the energy utilization rate. Comparing the water production ratios with the effective numbers of primary effect, secondary effect and tertiary effect, the data changes are shown in Figure 9. Under the condition that other process parameters are unchanged, with the increase of evaporator efficiency, the heat exchange area increases, and the water production ratio increases obviously, but the increasing speed of water production ratio will decrease. Therefore, increasing evaporation efficiency can effectively increase the water 
production ratio, but because the increase range of water production ratio will decrease, evaporation efficiency should not be excessively increased.

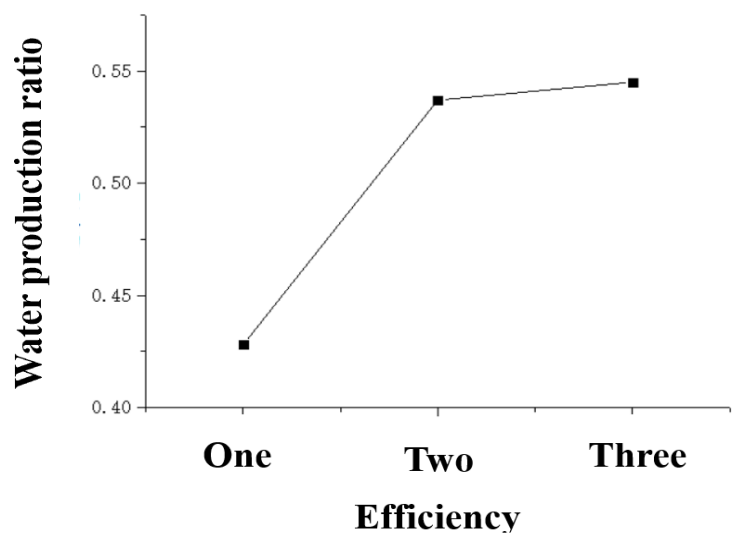

Fig. 8. Influence of evaporation efficiency number on water production ratio

\subsection{Analysis of influence of ejection position on water production ratio}

The steam ejector multi-effect evaporation seawater desalination system is simulated to study the influence of different ejector positions on the water production ratio of the steam ejector multi-effect evaporation seawater desalination system, and the results are shown in Table 2. With the forward movement of the ejector position of the steam ejector, the pressure of the ejected steam increases, and the ejector coefficient of the steam ejector increases, but the evaporator efficiency which can effectively utilize the low-pressure steam becomes less and less. The comprehensive effect of the two aspects results in the stronger improvement of the ejector coefficient when the ejector position of the steam ejector is farther behind, which leads to the larger water production ratio of the steam ejector multi-effect evaporation seawater desalination system.

Table 2. Simulation results of water yield and water production ratio under different injection positions

\begin{tabular}{|c|c|c|c|c|}
\hline \multicolumn{2}{|c|}{ Parameter } & \multicolumn{3}{c|}{ Evaporator efficiency } \\
\cline { 3 - 5 } \multicolumn{2}{|c|}{} & one & two & three \\
\hline $\begin{array}{c}\text { Hydraulic } \\
\text { discharge }\end{array}$ & $\mathrm{kg} / \mathrm{h}$ & 52.43 & 53.03 & 54.32 \\
\hline $\begin{array}{c}\text { Water } \\
\text { production } \\
\text { ratio }\end{array}$ & -- & 0.524 & 0.530 & 0.543 \\
\hline
\end{tabular}

\section{Conclusions}

In this paper, the steam ejector is numerically simulated under different operating conditions. The main conclusions are as follows:

(1) Under the same steam ejector structure, with the increase of working steam pressure, the mixing of working steam and ejected steam becomes more severe, the DIA shock wave structure increases, and gradually extends to the outlet of the mixing section, and the fluid near the injection inlet wall has partial reflux phenomenon; with the increase of the ejected steam pressure, the working steam and the ejected steam are mixed at the nozzle outlet, the momentum exchange effect of shear mixing is accelerated, and the DIA shock wave structure gradually gathers to the nozzle; with the increase of the pressure rise at the inlet and outlet of the ejected steam, the backflow phenomenon near the wall in the mixing chamber becomes more serious, and the DIA shock wave structure decreases.

(2) Under the condition of keeping other process parameters unchanged, with the increase of evaporation efficiency, the increase rate of water production ratio will decrease, and increasing evaporation efficiency can effectively increase water production ratio; With the forward movement of the ejector position of the thermal steam compressor, the pressure of the ejected steam increases, and the water production ratio of the steam ejector multi-effect evaporation seawater desalination system shows a downward trend.

(3) The influence of external parameters on the performance of steam ejector and the influence of ejector position on the water production ratio of steam ejector multi-effect evaporation desalination system can provide reference for the research and optimization of the performance of steam ejector and multi-effect evaporator coupling system, and improve the operation efficiency in the field of sewage treatment.

\section{References:}

1. Han Bing. Research on steam ejector and hybrid renewable energy system for MED seawater desalination system [D]. Beijing University of Technology, 2015.

2. Shuai Lu, Cai Zhen, Zhou Yihui, Xu Bo. Optimized design of MED-TVC system based on Lingo [J]. computers and applied chemistry, 2016,33(01):33-38.

3. Cai Haitao, Zhou Xiangyang, Hu Zaiding, Yang Lian, $\mathrm{Xu}$ Wenkui. Design and experimental study of TVC pump for low-temperature multi-effect seawater desalination plant $[\mathrm{J}]$. Journal of Vacuum Science and Technology, 2015,35(12):1495-1499.

4. Beijing Design Institute of Sinopec Group. SH/T 3118-2000, Design Code for Steam Jet Evacuator in Petrochemical Industry [S]. Beijing: State Administration of Petroleum and Chemical Industry, 2000:10-26.

5. Palacz M, Smolka J, Kus W, et al. CFD-based shape optimisation of a $\mathrm{CO} 2$ two-phaseejector mixing section[J]. Applied Thermal Engineering, 2016, 95: 62 69. 